Website: http://revistas.lamolina.edu.pe/index.php/acu/index

(C) Universidad Nacional Agraria La Molina, Lima - Perú

\title{
Características de productividad lechera de un establo de la cuenca de Cajamarca
}

\author{
Characteristics of productivity of a dairy farm of the dairy valley of Cajamarca
}

\author{
Agustín Eugenio Pallete Pallete ${ }^{* *}$; Zoila Mercedes Rodríguez Sánchez ${ }^{2}$ María Elisa Catalina García Salas ${ }^{3}$ \\ * Autor de correspondencia
}

\section{Resumen}

El objetivo del presente trabajo fue evaluar los niveles de productividad lechera de un establo del valle de Cajamarca entre los años 1991 al 2008. Como resultado de este estudio, se encontró una producción real de leche por campaña de $5379,8 \mathrm{~kg}$ con 391 días de lactación y de $4642,9 \mathrm{~kg}$ en 305 días. La máxima producción se alcanzó en el cuarto parto con $5129,8 \mathrm{~kg}$ de leche. Las producciónes de leche entre los años 1991 y 2008 mostraron una tendencia ascendente del orden de dos por ciento ( $2 \%$ ) anual. La edad al parto promedio encontrada fue de 60,3 meses, siendo el promedio de 33,6 meses al primer parto. El promedio del período de seca fue de 71,8 días. Para el intervalo entre partos se encontró un promedio de 16,0 meses. Se concluye que los niveles de productividad logrados por el establo Tres Molinos se comparan favorablemente con otros establos de la cuenca lechera de Cajamarca y de otras cuencas lecheras. Estos logros serían la consecuencia de la aplicación de apropiadas técnicas de manejo en el rebaño lechero.

Palabras clave: productividad; Cajamarca; vacas; leche.

\begin{abstract}
The aim of this study was analyze the level of milk productivity of a dairy farm from the valley of Cajamarca between the years 1991 to 2008. The results of this study shows a real milk production per lactation of $5379,8 \mathrm{~kg}$ with 391 days of length and of $4642,9 \mathrm{~kg}$ in 305 days. The maximum production was rich at the fourth calving with $5129,8 \mathrm{~kg}$ of milk. The milk production between the years 1991 and 2008 shows an ascendant tendency of the order of two percent ( $2 \%$ ) per year. The average age at calving was 60,3 months, and 33,6 months of age at the first calving. The average dry period was 71,8 days. The calving interval had an average of 16,0 months. It is concluded that the levels of milk productivity reached by the Tres Molinos dairy farm were positively compared with others dairy farms of Cajamarca and others areas of the country. These achievements were the results of the implementation of appropriated management practices in the dairy herd.
\end{abstract}

Keywords: productivity; Cajamarca; cows; milk.

\section{Introducción}

La producción de leche en el Perú en las últimas décadas prácticamente se ha duplicado y presenta un crecimiento promedio anual superior al cinco por ciento. Esto debido fundamentalmente al incremento de la productividad y al crecimiento de los rebaños existentes. Alrededor del sesenta por ciento de leche se produce en las cuencas lecheras especializadas de Cajamarca 18,0\%, Arequipa $17,8 \%$, Lima 17,8 \% y La Libertad 6,6 \%. Se considera que la cantidad de vacas lecheras a nivel nacional es de 895 mil con una producción promedio de $2182 \mathrm{~kg}$ por campaña, de las cuales Cajamarca posee 160 mil vacas lecheras con un promedio cercano a $2203 \mathrm{~kg}$ de leche por campaña / año. Según el Plan Nacional de Desarrollo (2006) los pequeños y medianos productores manejan el $34 \%$ de la población de vacunos (Costa, Sierra y Selva) y producen el $72 \%$ de la producción de leche nacional con un promedio de $2300 \mathrm{~kg}$ de leche por vaca campaña. Bernet (2000), menciona que para la cuenca de Cajamarca los factores que más afectan los ingresos de los ganaderos son la alta mortalidad, los largos intervalos entre partos y las ineficientes prácticas de conservación de forraje. Li Pun (2010), indica que la ganadería tiene un rol preponderante en la reducción de la pobreza ya que un alto porcentaje de pobres viven en áreas rurales. Siendo Cajamarca uno de los departamentos más pobres del país y contando con una considerable proporción de productores agropecuarios todo programa tendiente al desarrollo ganadero contribuirá a la disminución de los niveles de pobreza.

Con la finalidad de tener un mejor conocimiento de los niveles que se pueden lograr en la cuenca lechera de Cajamarca se planteó este trabajo de investigación con el objetivo de analizar los niveles de productividad lechera del establo Tres Molinos entre los años 1991 y 2008.

\section{Materiales y métodos}

El trabajo de campo de este estudio se realizó en el Establo "Tres Molinos" ubicado en la Campiña de Cajamarca y la fase de gabinete en el Programa de Investigación en

\footnotetext{
${ }^{1}$ Universidad Nacional Agraria La Molina, Lima, Perú. Email: aep@lamolina.edu.pe

${ }^{2}$ Practica Privada. Email: aizolcow22@gmail.com

${ }^{3}$ Facultad de Zootecnia, Universidad Nacional Agraria La Molina, Lima, Perú. Email: megarcia@lamolina.edu.pe
} 
Mejoramiento Animal de la Facultad de Zootecnia de la Universidad Nacional Agraria la Molina.

El establo se sitúa a 2600 msnm y cría ganado Holstein para lo cual posee un área aproximada de 30 ha, trabajando un sistema de producción semi-extensivo pastoreo durante el día y regresando a los corrales durante la noche, posee para ello pastos cultivados, asociación de rye grass y trébol blanco, en potreros con un sistema de rotación para evitar el sobrepastoreo. También realizan ensilaje de avena forrajera para las épocas de sequía. Las instalaciones del establo son: Potreros, bebederos, cunas para terneros y corrales para ordeño, partos, recría, vacas y toros. El sistema de ordeño empleado es manual con suplementación de concentrado durante el ordeño de la mañana, realizándose dos veces al día (4:00 am y 4:00 pm) y teniendo una duración promedio de dos horas por ordeño.

Para este trabajo se emplearon los cuadernos de campo y tarjetas de vacas del establo para la recolección de datos que básicamente consistió en: la identificación de las vacas: número, raza, fecha de nacimiento, parto y seca. Así como, la producción real de leche: por campaña y en 305 días de cada vaca. En la fase de análisis, evaluación y procesamiento de los datos se utilizó la hoja de excel en una computadora del Programa de Investigación en Mejoramiento Animal.

En esta investigación se han considerado los siguientes parámetros de Productividad de vacas lecheras. Producción real por campaña: leche $(\mathrm{kg})$ y duración (días). Producción real en 305 días: leche (kg). Edad al parto (meses). Período de seca (días), e Intervalo entre partos (meses). El estudio tuvo tres niveles: General: Se evaluaron las características para todo el período de dieciocho años: 1991 al 2008. Por Años: Se analizaron las características para cada año desde 1991 - 2008. Por Partos: Se calcularon las características para los partos del primero al séptimo.

Se presentan las estadísticas descriptivas, media y error estándar de las características de productividad lechera analizadas. Se utilizó un modelo estadístico lineal para la producción de leche, por campaña y en 305 díass. Los procedimientos estadísticos de los datos fueron realizados utilizando el paquete Statistical Analysis System (SAS).

\section{Resultados y discusión}

De acuerdo a García y Gómez (2005), indican que el establo Tres Molinos corresponde a la categoría de granjas más progresistas PE-13, que representan los sistemas lecheros con gestión más comercial de Cajamarca.

\section{Producción Por Campaña}

General: El promedio de producción de leche por campaña fue de $5379,8 \mathrm{~kg}$ de leche con una duración de 391 días, para las 375 lactaciones correspondientes al período de dieciocho años de estudio. Alba (1980), realizó su investigación con 3651 lactaciones de la cuenca de Cajamarca encontrando una producción real por campaña de $4696,7 \mathrm{~kg}$ con una duración de 347,1 días. Cerna (1990), en su trabajo con 11108 lactaciones de la cuenca de
Cajamarca encontró una producción real por campaña de 4 084,4 kg de leche con una duración de 335,2 días. García (1992), realizó su investigación de la cuenca de Lima encontrando una producción real de leche por campaña de $4364 \mathrm{~kg}$ en 328 días de lactación. Pallete et al. (1993), del análisis de sus datos encontramos una producción de 3 222,7 kg de leche para la cuenca de Cajamarca. Pimentel (1994), en su trabajo de investigación en Arequipa reporta una producción por campaña de $4857,5 \mathrm{~kg}$ de leche en 324 días. Valera (1996), en su investigación realizada en la cuenca de Lima encontró una producción real por campaña de $4543 \mathrm{~kg}$ de leche con una duración de 339 días. Ruiz (2000), en su trabajo de investigación reportó para la cuenca de Lima producciónes de $4750 \mathrm{~kg}$ con 330 días de lactaciones. Casapia (2001), trabajó en hatos lecheros de Majes - Arequipa encontrando producciónes por campaña de $6064 \mathrm{~kg}$ de leche con una duración de 328 días. Campos (2001), encontró para la cuenca de La Libertad producciónes por campaña de $4086 \mathrm{~kg}$ de leche con 330 días de duración. Maldonado (2008) encontró una producción por campaña de $5194,5 \mathrm{~kg}$ de leche con una duración de 397 días de lactación. Podemos apreciar que las producciónes reales por campañas encontradas en esta investigación se comparan favorablemente con los resultados encontrados en otros estudios realizados en años similares en otras cuencas lecheras. Los altos niveles alcanzados en este establo tendrían su fundamento en las buenas prácticas de crianza, alimentación, y reproducción realizadas en el establo.

Por años: En la Tabla 1 se muestran, las producciónes de leche por campaña a través de los años, y que muestran una variación de $4271 \mathrm{~kg}$ en el año 1992 y de $6125 \mathrm{~kg}$ en el año 2002. En líneas generales presentan una tendencia ascendente a través de los dieciocho años estudiados. Pimentel (1994), trabajando lactaciones de Majes Arequipa encontró producciónes de leche por campaña que variaron de $5180,5 \mathrm{~kg}$ con una duración de 353 días en 1989 a 4 $057,8 \mathrm{~kg}$ con una duración de 284 días en 1993. Valera (1996), en su amplia investigación realizada en la cuenca de Lima reporta producciónes por campaña de $4891 \mathrm{~kg}$ en 1976 a $5000 \mathrm{~kg}$ en 1986.

Por partos: En la Tabla 2 se indican las producciónes de leche por campaña a través de los partos, y muestran un rendimiento de $4787 \mathrm{~kg}$ en el primer parto y lográndose la máxima producción en el cuarto parto con $5817 \mathrm{~kg}$. En líneas generales presentan una tendencia ascendente a través de los siete partos considerados.

Rosemberg (1976), indica para la cuenca lechera de Lima producciónes de leche por campaña que van de $4506,6 \mathrm{~kg}$ en el primer parto a $5140,4 \mathrm{~kg}$ de leche al séptimo parto, alcanzando la máxima producción al cuarto parto con 5 389,2 kg de leche. Pimentel (1994), en su investigación en la cuenca de Majes - Arequipa reporta producciónes de leche por campaña de $4220,2 \mathrm{~kg}$ en el primer parto y $5250,7 \mathrm{~kg}$ en el séptimo parto, la máxima 
producción se logró en el quinto parto con $5622 \mathrm{~kg}$ de leche. Valera (1996), en su trabajo de investigación en la cuenca lechera de Lima reporta las siguientes producciónes de leche según los partos: en el primer parto $4284 \mathrm{~kg}$, la máxima producción en el cuarto parto con $4728 \mathrm{~kg}$ y 4526 $\mathrm{kg}$ en el séptimo parto.

Tabla 1. Producción por campaña y en 305 días: por años

\begin{tabular}{lccccccccccc}
\hline & \multicolumn{4}{c}{ Por campaña } & \multicolumn{4}{c}{ En 305 Días } \\
\cline { 2 - 11 } Año & \multicolumn{3}{c}{ Leche - KG } & \multicolumn{3}{c}{ Duración } & \multicolumn{3}{c}{ LECHE - KG } \\
\cline { 2 - 11 } & N & PROM & \pm E. E. & N & PROM \pm E. E. N & PROM & \pm E. E. \\
\hline 1991 & 5 & 4 & 688,6 & 965,9 & 5 & 406,2 & 91,2 & 2 & 3 & 667,5 & 364,5 \\
1992 & 5 & 4 & 271,0 & 657,6 & 5 & 357,8 & 34,3 & 4 & 3 & 894,0 & 382,7 \\
1993 & 13 & 5 & 296,8 & 317,4 & 13 & 403,5 & 23,3 & 13 & 4 & 324,3 & 165,1 \\
1994 & 20 & 4 & 825,9 & 295,2 & 20 & 378,8 & 22,7 & 15 & 4 & 036,6 & 142,2 \\
1995 & 28 & 4 & 961,7 & 210,9 & 28 & 387,2 & 17,4 & 22 & 4 & 168,0 & 120,3 \\
1996 & 27 & 5 & 642,3 & 243,3 & 27 & 399,0 & 13,9 & 26 & 4 & 534,9 & 127,3 \\
1997 & 23 & 5 & 680,4 & 277,9 & 23 & 412,4 & 26,6 & 18 & 4 & 652,6 & 114,1 \\
1998 & 38 & 4 & 803,5 & 288,4 & 38 & 411,6 & 26.0 & 30 & 4 & 106,5 & 153,3 \\
1999 & 22 & 5 & 892,1 & 550,4 & 22 & 447,5 & 40,3 & 18 & 4 & 721,0 & 224,3 \\
2000 & 22 & 4 & 656,0 & 399,7 & 22 & 350,5 & 30,5 & 14 & 4 & 558,5 & 198,1 \\
2001 & 21 & 5 & 991,1 & 421,6 & 21 & 433,5 & 31,1 & 17 & 4 & 629,5 & 168,7 \\
2002 & 12 & 6 & 125,3 & 655,4 & 12 & 386,5 & 61,5 & 9 & 5 & 476,3 & 272,9 \\
2003 & 23 & 6 & 050,4 & 502,4 & 23 & 361,8 & 33,5 & 16 & 5 & 582,9 & 270,9 \\
2004 & 21 & 5 & 841,3 & 453,2 & 21 & 375,1 & 28,2 & 15 & 5 & 118,8 & 211,5 \\
2005 & 23 & 5 & 153,9 & 498,5 & 23 & 343,6 & 32,1 & 14 & 5 & 170,8 & 224,9 \\
2006 & 24 & 5 & 255,2 & 523,0 & 24 & 368,8 & 35,6 & 15 & 5 & 020,4 & 342,7 \\
2007 & 21 & 5 & 620,1 & 483,3 & 21 & 397,0 & 35,3 & 18 & 4 & 988,0 & 240,5 \\
2008 & 27 & 5 & 441,3 & 287,7 & 27 & 391,4 & 18,2 & 25 & 4 & 579,8 & 179,6 \\
\hline
\end{tabular}

\section{Producción en 305 días}

General: El promedio de producción en 305 días fue de 4 $642,9 \mathrm{~kg}$ de leche para las 291 lactaciones correspondientes al período de dieciocho años. Estas producciónes ya no tienen la influencia de los días en lactaciones, por lo que son mejores para efecto de comparaciones. Rosemberg (1976), en su trabajo de investigación en la cuenca de Lima reporto producciónes promedio de $5125 \mathrm{~kg}$ de leche para los años 1956 a 1972. Alba (1980), en su trabajo realizado en la cuenca de Cajamarca encontró una producción en 305 días de 4 195,3 $\mathrm{kg}$ de leche. Oliva (1987), en su investigación con 17161 lactaciones de la cuenca de Lima reporta 4 443,5 kg de leche en 305 días. Cerna (1990), reporta en su trabajo de investigación con 6700 lactaciones de Cajamarca una producción de $4008,7 \mathrm{~kg}$ de leche en 305 días. García (1992), encontró una producción en 305 días de $4217 \mathrm{~kg}$ de leche en su investigación en la cuenca lechera de Lima. Pimentel (1994), reporta una producción de 4 626,2 kg de leche en 305 días para la Irrigación Majes - Arequipa. Valera (1996), reporta una producción real en 305 días de $4349 \mathrm{~kg}$ de leche para el período 1976 1986. Ruiz (2000), reportó para la cuenca lechera de Lima producciónes en 305 días de $4644 \mathrm{~kg}$ de leche. Trabajando con lactaciones de Majes - Arequipa. Casapia (2001), encontró producciónes de $5856 \mathrm{~kg}$ de leche en 305 días. Campos (2001), realizó su investigación con datos de La Libertad y reporto producciónes de $3939 \mathrm{~kg}$ de leche en
305 días. Maldonado (2008), en su investigación con datos de la cuenca lechera de Lima reporta una producción de $4355,7 \mathrm{~kg}$ de leche en 305 días. Rosales (2012), en su investigación en un establo en la cuenca de Lima indica una producción de $6811 \mathrm{~kg}$ de leche en 305 días.

Los resultados obtenidos para producciónes reales en 305 días en esta investigación se comparan favorablemente, en la mayoría de los casos, con los resultados de otros estudios similares realizados en diferentes cuencas lecheras del país. Las buenas prácticas de recría, alimentación y reproducción realizadas en el establo en los años que cubre esta investigación sería el sustento de los resultados encontrados.

Tabla 2. Producción por campaña y en 305 días: por partos

\begin{tabular}{|c|c|c|c|c|c|c|c|c|c|}
\hline \multirow{3}{*}{ Parto } & \multicolumn{6}{|c|}{ Por campaña } & \multirow{2}{*}{\multicolumn{3}{|c|}{$\begin{array}{l}\text { En } 305 \text { días } \\
\text { Leche }-\mathrm{KG}\end{array}$}} \\
\hline & \multicolumn{3}{|c|}{ Leche - KG } & \multicolumn{3}{|c|}{ Duración - días } & & & \\
\hline & $\mathrm{N}$ & PROM & \pm E. E. & $\mathrm{N}$ & PROM & E. E. & $\mathrm{N}$ & PROM = & \pm E. E. \\
\hline 1 & 113 & 4814,7 & 159,5 & 113 & 382,7 & 13,0 & 83 & 4112,4 & 77,2 \\
\hline 2 & 82 & 5263,5 & 176,3 & 82 & 386,8 & 14,4 & 65 & 4574,7 & 86,7 \\
\hline 3 & 63 & 5715,8 & 246,4 & 63 & 398,0 & 19,0 & 51 & 4872,3 & 141,0 \\
\hline 4 & 48 & 5916,2 & 305,9 & 48 & 389,8 & 17,8 & 39 & 5129,8 & 151,4 \\
\hline 5 & 31 & 5734,6 & 373,2 & 31 & 417,7 & 26,8 & 25 & 4816,4 & 163,7 \\
\hline 6 & 23 & 5356,3 & 460,1 & 23 & 391,7 & 32,7 & 17 & 4819,6 & 177,3 \\
\hline 7 & 9 & 7364,8 & 733,6 & 9 & 445,4 & 60,4 & 8 & 5776,7 & 356,3 \\
\hline
\end{tabular}

Por Años: En la Tabla 1 se muestran las producciónes en 305 días correspondientes a los años 1991 al 2008. Se pueden apreciar que las producciónes de leche por años tienen una variación de $3668 \mathrm{~kg}$ en 1991 a $5583 \mathrm{~kg}$ en el año 2003. Esto significa un incremento de $1815 \mathrm{~kg}$ de leche en los primeros trece años una cifra muy respetable para la cuenca de Cajamarca. Así mismo muestran en general una tendencia ascendente del orden del dos por ciento (2 $\%$ ) a través de los años del estudio realizado en el establo. Oliva (1987), realizo su investigación con lactaciones de la cuenca de Lima, encontrando que las producciónes varían de $4778,3 \mathrm{~kg}$ en el año 1970 a $4291,0 \mathrm{~kg}$ en el año 1975. Pimentel (1994), realizo su estudio con lactaciones de la cuenca lechera de Majes Arequipa encontrando producciónes de 305 días que variaron de $4579,5 \mathrm{~kg}$ en el año 1989 a 4 165,8 en 1993. Valera (1996), reporta para su trabajo en la cuenca lechera de Lima producciónes de leche en 305 días de $4584 \mathrm{~kg}$ en 1976 a $4770 \mathrm{~kg}$ en 1986. Rosales (2012), realizó su estudio en un establo de la cuenca de Lima encontrando en vacas de primer parto variaciones de $5678 \mathrm{~kg}$ en el año 1995 a 6914 en el año 2002 siendo el año 2000 el de máxima producción con $6997 \mathrm{~kg}$ de leche. Málaga (2016), en su investigación realizada en la Irrigación Santa Rita - Arequipa indica que las producciónes por vaca para el período 2005 2010 mostraron una tendencia ascendente. En la Figura 1 se pueden apreciar las variaciones de las producciónes de leche en 305 días a través de los dieciocho años de esta investigación, notándose claramente la tendencia ascendente. Las producciónes de leche en 305 días por año, mostraron diferencias altamente significativas. $(\alpha<0,01)$. 
Por Partos: En la Tabla 2, se encuentran las producciónes de leche en 305 días correspondientes a los partos primero al séptimo donde se puede apreciar que en el primer parto arrancan con $4112,4 \mathrm{~kg}$ y que las producciónes en 305 días ascienden hasta alcanzar la máxima producción de 5 $129,8 \mathrm{~kg}$ de leche en el cuarto parto y luego comienzan a descender hasta el sexto parto con $4819,6 \mathrm{~kg}$ de leche. Esta situación está ampliamente sustentada por que el desarrollo corporal y del sistema mamario de las vacas va acorde con su edad. Rosemberg (1976), trabajando con lactaciones de la cuenca de Lima encontró variaciones de producciónes en 305 días de $4376,1 \mathrm{~kg}$ en el primer parto a $5189,0 \mathrm{~kg}$ de leche en el cuarto parto. Oliva (1987), en la cuenca de Lima encontró una producción de leche que varió de $4109,4 \mathrm{~kg}$ en el primer parto a 4 474,8 en el séptimo parto, alcanzando la máxima producción de 4 665,9 kg de leche en el cuarto parto. Pimentel (1994), realizó su investigación en Majes Arequipa encontrando que las producciónes en 305 días tenían una variación de $4044,9 \mathrm{~kg}$ de leche en el primer parto y alcanzando la máxima producción en el sexto parto con $5419,5 \mathrm{~kg}$. Valera (1996), en su investigación en la cuenca de Lima reporta producciónes de leche para el primer parto de 3 $993 \mathrm{~kg}$ lográndose la máxima producción el cuarto parto con $4598 \mathrm{~kg}$ de leche. Rosales (2012), en su estudio en un establo de la cuenca de Lima encontró producciónes de 6 $543 \mathrm{~kg}$ al primer parto, lográndose la máxima producción de $7243 \mathrm{~kg}$ de leche en el sexto parto.

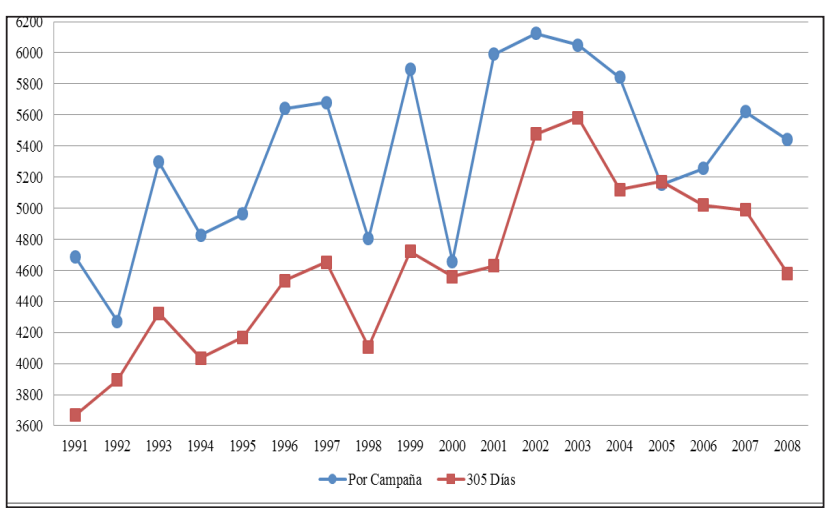

Figura 1. Producción por años

En la Figura 2 se pueden apreciar las variaciones en las producciónes en 305 días por partos y según los resultados de este estudio se logran las máximas producciónes en el cuarto parto, estos resultados coinciden con la mayoría de investigaciones realizadas en diferentes cuencas lecheras en el país. Las producciónes de leche en 305 días por número de parto mostraron diferencias altamente significativas $(\alpha$ $<0,01)$.

\section{$\underline{\text { Edad - Meses }}$}

General: El promedio de edad al parto fue de 60,3 meses para los 375 datos considerados, y al primer parto fue de 33,6 meses correspondientes a 113 datos, para el período de dieciocho años de estudio. Alba (1980), en su investigación con lactaciones de Cajamarca encontró para el período 1967 a 1975 un promedio de edad al parto de 62,6 meses. Oliva (1987), trabajando en la cuenca de Lima encontró una edad promedio al parto de 58,4 meses. Cerna (1990), trabajando con datos de Cajamarca para el período de 1976 a 1986, encontró una edad promedio al parto de 62,0 meses, y al primer parto la edad promedio fue de 34 meses. García (1992), en la cuenca lechera de Lima encontró una edad promedio al parto de 64,8 meses. Pimentel (1994), en Majes - Arequipa reporta una edad promedio de 54 meses y una edad al primer parto de 30,2 meses. Valera (1996), en la cuenca lechera de Lima reporta una edad al primer parto de 33 meses y una edad promedio de 65 meses. Maldonado (2008), en la cuenca lechera de Lima reporta una edad al parto de 60,6 meses. Marin (2011) en su investigación en Cajamarca encontró 34,3 meses como edad al primer parto. Rosales (2012), en la cuenca de Lima encontró una edad al parto promedio de 52,1 meses. En relación a la edad al parto los resultados de esta investigación tanto en la edad al primer parto como en la edad promedio para todos los partos son muy similares a los resultados de diferentes estudios realizados en otras cuencas lecheras. Estos resultados serian el reflejo de las practicas de recría y reproductivas realizadas en el establo materia de esta investigación.

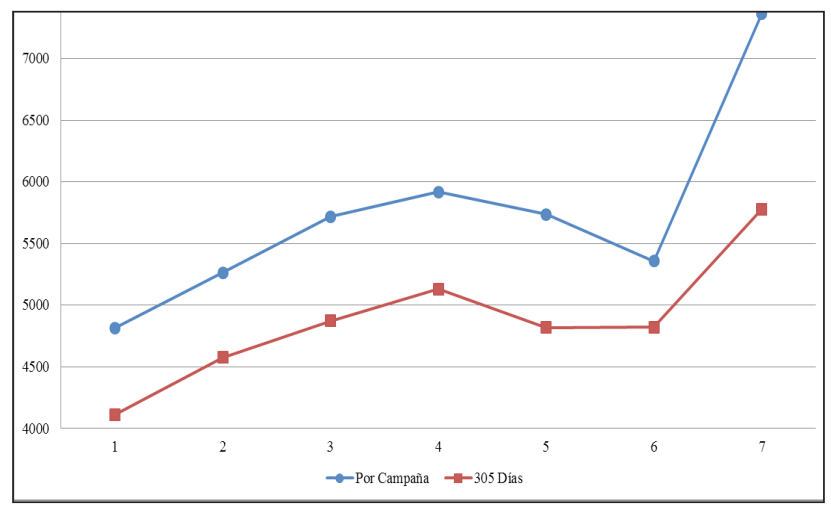

Figura 2. Producción por partos

Por Años: En la Tabla 3 se pueden apreciar las edades al parto promedio para los años que reflejan que el establo se inicio con vacas de primer parto incrementándose con el tiempo hasta estabilizarse en los últimos años con una edad muy cercana a los 60 meses como promedio del establo. Pimentel (1994), trabajando con lactaciones de Majes Arequipa encontró para edad al primer parto 28,6 meses en el año 1989 y 28,6 meses en el año 1993 es decir sin mostrar ninguna tendencia definida. Rosales (2012), en su investigación de la cuenca de Lima encontró una edad de 4,6 años en 1995 y 4,2 años en el 2002 siendo la máxima edad de 4,7 años en 1998.

Por Partos: En la Tabla 4 se puede apreciar las edades al parto correspondientes del primero al séptimo parto, las que van de 33,6 meses en el primer parto hasta 122,1 meses en el séptimo parto. Rosemberg (1976), trabajando con 
lactaciones de la cuenca lechera de Lima reporta una edad al primer parto de 30,2 meses y al séptimo parto de 110,4 meses. Oliva (1987), en su investigación con lactaciones de la cuenca de Lima encontró que la edad al parto variaba de 31,1 meses en el primer parto a 109,7 meses al séptimo parto. Pimentel (1994), con su base de datos de Majes Arequipa encontró que la edad al primer parto era de 30,2 meses y que aumento gradualmente hasta 108,8 meses en el séptimo parto. Rosales (2012), en su investigación en un establo en la cuenca de Lima, reporta una edad al primer parto de 27,5 meses, hasta 113,9 meses en el séptimo parto Tanto la edad por años como la edad por partos coinciden en líneas generales con otros estudios realizados lo que indicarían que el establo materia de esta investigación realizó las prácticas de manejo recomendadas para la crianza de ganado lechero.

Tabla 3. Edad - Periodo de seca - Intervalo entre partos: Por años

\begin{tabular}{|l|r|r|r|r|r|r|r|r|r|}
\hline \multirow{2}{*}{ Año } & \multicolumn{4}{|c|}{ Edad } & \multicolumn{3}{|c|}{ Periodo de seca } & \multicolumn{3}{|c|}{ Int. entre partos } \\
\cline { 2 - 12 } & N & Prom & \pm E. E. & N & Prom & \pm E. E. & N & Prom \pm E. E. \\
\hline 1991 & 5 & 28,2 & 1,4 & -- & -- & -- & -- & -- & -- \\
\hline 1992 & 5 & 37,8 & 2,5 & 4 & 70,2 & 6,7 & 4 & 11,7 & 0,5 \\
\hline 1993 & 13 & 42,0 & 3,2 & 7 & 65,8 & 10,0 & 7 & 16,4 & 1,9 \\
\hline 1994 & 20 & 38,8 & 3,1 & 8 & 64,7 & 2,3 & 8 & 14,0 & 0,6 \\
\hline 1995 & 28 & 50,7 & 3,0 & 22 & 65,9 & 1,8 & 22 & 14,3 & 0,6 \\
\hline 1996 & 27 & 60,4 & 3,5 & 24 & 70,6 & 4,8 & 24 & 15,0 & 0,7 \\
\hline 1997 & 23 & 66,0 & 4,4 & 19 & 63,5 & 4,6 & 19 & 15,3 & 0,5 \\
\hline 1998 & 38 & 67,6 & 3,8 & 29 & 95,3 & 8,4 & 29 & 15,9 & 0,6 \\
\hline 1999 & 22 & 83,6 & 5,1 & 20 & 77,4 & 8,5 & 20 & 16,7 & 0,7 \\
\hline 2000 & 22 & 77,7 & 5,8 & 19 & 74,7 & 4,9 & 19 & 18,4 & 0,9 \\
\hline 2001 & 21 & 73,3 & 7,5 & 14 & 72,2 & 4,0 & 14 & 18,3 & 1,2 \\
\hline 2002 & 12 & 78,5 & 10,5 & 10 & 73,9 & 9,8 & 10 & 18,1 & 1,4 \\
\hline 2003 & 23 & 61,5 & 8,0 & 13 & 64,5 & 7,5 & 13 & 15,9 & 0,9 \\
\hline 2004 & 21 & 51,1 & 6,6 & 13 & 65,5 & 7,3 & 13 & 13,6 & 0,6 \\
\hline 2005 & 23 & 55,3 & 7,1 & 15 & 65,7 & 5,4 & 15 & 16,3 & 1,6 \\
\hline 2006 & 24 & 55,0 & 4,4 & 20 & 77,5 & 6,2 & 20 & 16,8 & 0,9 \\
\hline 2007 & 21 & 54,7 & 5,1 & 15 & 66,6 & 7,8 & 15 & 15,5 & 0,9 \\
\hline 2008 & 27 & 57,1 & 4,9 & 19 & 60,5 & 2,8 & 19 & 16,7 & 1,0 \\
\hline
\end{tabular}

\section{Período de Seca - Días}

General: Para los dieciocho años que cubre la presente investigación el período de seca promedio fue de 71,8 días correspondientes a 271 lactaciones. Alba (1980), realizó su investigación con lactaciones de Cajamarca encontrando un período de seca de 94,4 días para el período de 1967 a 1975. Cerna (1990), reporta un período de seca de 82,4 días en lactaciones de Cajamarca para el período de 1976 a 1986. García (1992), encontró en su investigación 80 días de período de seca en la cuenca lechera de Lima. Pallete et al (1993), reporta un período de seca de 121 días para sus datos de la cuenca lechera de Cajamarca. Pimentel (1994), reporta un período de seca de 79 días para su trabajo realizado en Majes Arequipa. Valera (1996), en su trabajo de investigación en la cuenca lechera de Lima un período de seca de 80 días. Rosales (2012), reporta para un establo de la cuenca de Lima un período de seca de 70 días.
El período de seca de 71,8 días encontrado en el presente trabajo de investigación se compara favorablemente con los resultados de otros estudios realizados en otras cuencas lecheras en similares períodos de tiempos. Las buenas prácticas de manejo principalmente de registros pecuarios y reproducción realizadas en el establo durante el período estudiado justifican estos resultados, básicamente por ser de crianza semi-extensiva en sierra.

Tabla 4. Edad -Periodo de Seca - Intervalo entre partos: Por partos

\begin{tabular}{rrrrrrrrrr}
\hline \multirow{2}{*}{ Parto } & \multicolumn{4}{c}{ Edad } & \multicolumn{4}{c}{ Periodo de seca } & \multicolumn{3}{c}{ Int. entre partos } \\
\cline { 2 - 10 } & N & PROM & \pm E. E. & N & PROM \pm E. E. & N & PROM & \pm E. E. \\
\hline 1 & 113 & 33,6 & 0,6 & -- & -- & -- & -- & -- & -- \\
2 & 82 & 47,5 & 0,8 & 82 & 66,1 & 2,2 & 82 & 15,4 & 0,4 \\
3 & 63 & 62,4 & 1,1 & 63 & 73,2 & 3,7 & 63 & 15,7 & 0,4 \\
4 & 48 & 78,1 & 1,4 & 50 & 79,1 & 5,0 & 50 & 16,6 & 0,6 \\
5 & 31 & 91,5 & 1,8 & 33 & 64,6 & 3,4 & 33 & 16,0 & 0,5 \\
6 & 23 & 108,2 & 2,3 & 24 & 75,0 & 5,9 & 24 & 16,4 & 0,9 \\
7 & 9 & 122,1 & 2,9 & 12 & 83,1 & 11,3 & 12 & 17,9 & 1,1 \\
\hline
\end{tabular}

Por Años: En la Tabla 3 se pueden apreciar los días en seca a través de los años en estudio, encontrándose que varían de 61 días en el año 2008 y 95 días en el año 1998, sin mostrar una tendencia definida a través de los años estudiados. Pimentel (1994), en su estudio en la cuenca de Majes Arequipa encontró períodos de seca de 74,8 días en 1991 a 84,6 días en 1993. Valera (1996), en su estudio realizado en la cuenca de Lima reporta períodos de seca que varían de 74 días en 1976 a 89 días en 1986. Rosales (2002), trabajando datos de un establo de la cuenca de Lima reporta un período de seca para 1995 de 55 días y para el año 2002 de 75 días. En la Figura 3 se pueden apreciar las variaciones de los días en seca a través de todo el período del estudio los cuales no muestran una tendencia definida. Los períodos de seca por año, mostraron diferencias altamente significativas $(\alpha<0,01)$.

Por Partos: En la Tabla 4 se pueden apreciar los resultados del período de seca en días correspondientes del segundo al séptimo parto, variando entre 66,1 días en el quinto parto a 83,1 en el séptimo parto. En líneas generales las cifras presentan una tendencia alcista lo cual parece lógico ya que a través de los partos las vacas son menos persistentes y más difíciles de preñar, factores que incrementan los períodos de seca. Pimentel (1994), en un estudio de la cuenca de Majes Arequipa encontró período de secas de 75,6 días en el segundo parto a 81,9 días en el séptimo parto. Valera (1996), indica en su investigación en la cuenca de Lima períodos de seca de 78 días en el segundo parto a 81 días en el séptimo parto. Rosales (2012), reporta para su trabajo en un establo en la cuenca lechera de Lima un período de seca de 61 días en el segundo parto y de 78 días en el sexto parto. En la Figura 4 se pueden apreciar las variaciones de los días en seca a través de los partos observándose una tendencia alcista. Los períodos de seca 
por partos mostraron solo diferencias significativas $(\alpha<$ $0,05)$.

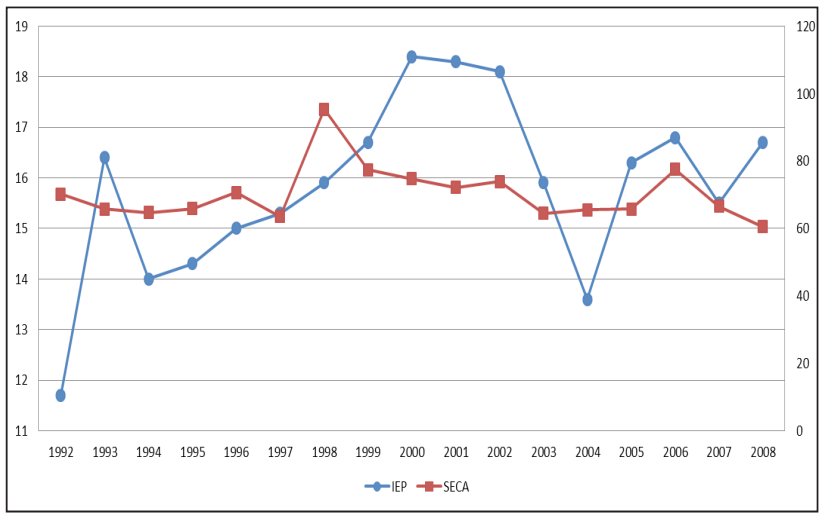

Figura 3. Periodo de seca-Intervalo entre partos: Por años

Intervalo entre Partos - Meses

General: Para los dieciocho años del estudio el intervalo entre partos fue de 16,0 meses correspondiente a 271 lactaciones. Siendo lo recomendado de 14 meses de intervalo entre partos, esta cifra puede considerarse muy buena para las condiciones del presente estudio. Del análisis de los datos de Alba (1980), se encontró un intervalo entre partos de 14,5 meses para lactaciones de establos de la cuenca de Cajamarca. Vassallo (1980), trabajando con ganado Brown Swiss encontró un intervalo entre partos de 14,3 meses. Cerna (1990), reporta cifras que determinaron un intervalo entre partos de 13,7 meses trabajando con datos de Cajamarca. García (1992), en la cuenca de Lima encontró 14 meses de intervalos entre partos. Pallete et al (1993), en su investigación encontraron 16,3 meses como promedio de intervalo entre partos para Cajamarca. Pimentel (1994), para su trabajo realizado en Majes Arequipa reporta un intervalo entre partos de 13,7 meses. Valera (1996), en la cuenca de Lima reporta 14,5 meses de intervalo entre partos. Marin (2011), en su investigación evaluó nueve (9) fundos del Valle de Cajamarca encontrando un intervalo entre partos de 16,7 meses. Rosales (2012), encontró en un establo de la cuenca de Lima un intervalo entre partos de 14 meses. Si bien es cierto los valores de intervalo entre parto encontrado en esta investigación son relativamente altos, cuando se compara con otros estudios de otras cuencas encontramos que se encuentran en posición intermedia, pero muy buenos para crianza semi-extensiva de Sierra.

Por Años: En la Tabla 3 se pueden apreciar los intervalos entre partos en meses a través de los años en estudio, notándose que varían entre 11,7 en el año 1992 y 18,4 meses en el 2000. Esto significaría que en los últimos años se volvieron a aplicar buenas prácticas de manejo, especialmente reproductivas, para recuperar los mejores promedios de intervalo entre partos. Pimentel (1994), en su estudio en la cuenca de Majes Arequipa encontró un intervalo entre partos de 13,3 meses en 1990 y 13,3 meses 1993. Valera (1996), en su estudio en la cuenca de Lima encontró un intervalo entre partos de 14,5 meses en 1976 a 14,8 meses en 1986. Rosales (2012), en su trabajo realizado en un establo de la cuenca de Lima reporta un intervalo entre partos de 13,9 meses para 1995 y 14,7 meses para el año 2002 siendo el máximo 15,1 meses en el año 1999. En la Figura 3 se pueden apreciar las variaciones de los intervalos entre partos a través de los años, los cuales mostraron diferencias altamente significativas $(\alpha<0,01)$.

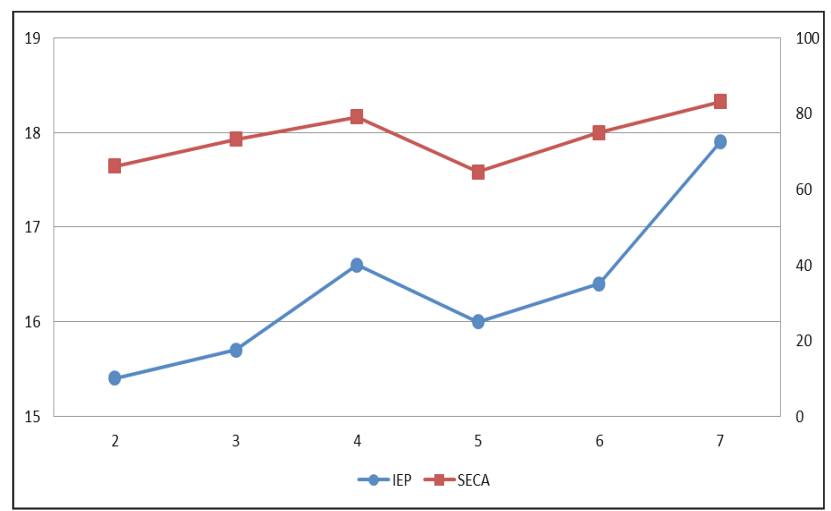

Figura 4. Periodo de seca-Intervalo entre partos:

Por partos

Por Partos: En la Tabla 4 se pueden apreciar los resultados del intervalo entre partos en meses, correspondientes del segundo al séptimo parto, variando entre 15,5 meses en el segundo parto y 17,7 meses en el séptimo parto, es decir una tendencia alcista. Estas cifras pueden considerarse muy aceptables dado las condiciones del estudio y debido a que a medida que se incrementa el número de parto las vacas son más difíciles de preñar y consecuentemente el intervalo entre partos tiende a incrementarse. Pimentel (1994), en su estudio en la cuenca de Majes Arequipa reporta cifras de 13,6 meses en el segundo parto, 14,2 meses en el quinto parto y 13,6 meses en el séptimo parto. Valera (1996), en su investigación en la cuenca de Lima reporta un intervalo entre partos de 14,8 meses en el segundo parto y 14,5 meses en el séptimo parto. Rosales (2012), en su investigación en un establo en la cuenca de Lima encontró 14,1 meses de intervalo entre partos en el segundo parto y 15,3 meses en el séptimo parto. En la Figura 4 se pueden apreciar las variaciones de los intervalos entre partos a través de los siete partos estudiados, las cuales no mostraron diferencias significativas (n.s.).

\section{Conclusiones}

Los niveles de producción real de leche logrados por el establo Tres Molinos por campaña fueron de $5379,8 \mathrm{~kg}$ con 391 dias de duración y de $4642,9 \mathrm{~kg}$ en 305 días. Estos resultados se comparan favorablemente con los alcanzados en Cajamarca y otras cuencas lecheras del país, para condiciones similares de crianza semi - extensiva en Sierra. La tendencia ascendente del dos por ciento anual (2 \%) de las producciónes de leche lograda entre los años 1991 y 2008 demuestran que se aplicarón apropiadas técnicas de 
manejo en el rebaño lechero del establo estudiado.

\section{Literatura citada}

Alba S. B. 1980. Pruebas de Progenie de Toros Holstein usados en la cuenca lechera de Cajamarca Tesis Ing. Zootecnista, Universidad Nacional Agraria La Molina, Lima, Perú.

Bernet, T. 2000. The Peruvian Dairy Sector, Farm Perspectives, Development Strategies and Policy Options. Swiss Federal Institute of Technology Zurich.

Campos, R. 2001. Características Productivas y Reproductivas de Vacas Holstein de la cuenca lechera de La Libertad (1976 - 1987). Trabajo Monográfico Ing. Zootecnista, Universidad Nacional Agraria La Molina, Lima, Perú.

Casapia, C. R. 2001. Evaluación Reproductiva y de Producción de Hatos del Servicio de Productividad Lechera en la Irrigación de Majes 1999-2001. Arequipa, Perú.

Garcia, S. M. 1992. Estimación de los Valores Genéticos del Ganado Lechero de la cuenca lechera de Lima - Tesis Magister Scientiae, Escuela PostGrado, Especialidad de Producción Animal, Universidad Nacional Agraria La Molina, Lima, Perú.

Garcia, O. Gomez, C. 2006. The Economics of Milk Production in Cajamarca, Perú, with Particular Emphasis on Small-Scale Producers. FAO. International Farm Comparison Network.

Li Pun, H. 2010. El Rol de la Ganadería en la Reducción de la Pobreza, Seguridad Alimentaria y el Medio Ambiente: Una Visión Global. Simposium en Zootecnia y Ciencia Animal, Universidad Nacional Agraria La Molina, Lima, Perú.

Malaga, N. A. 2016. Características Socio - Ganaderas y niveles de Productividad de Establos Lecheros de la Irrigación Santa Rita en Arequipa - Tesis Magister Scientiae - Escuela Postgrado, Especialidad de Producción Animal, Universidad Nacional Agraria La Molina, Lima, Perú.

Maldonado, C. J. 2008. Influencia de los Toros Holstein Nacionales y Extranjeros sobre la Productividad en la cuenca lechera de Lima (1978 - 1985). Tesis Ing. Zootecnista, Universidad Nacional Agraria La Molina, Lima, Peruú

Marin, A. W. 2011. Estudio de la Producción Lechera de la raza Holstein del Distrito de Cajamarca. Tesis Ing. Zootecnista, Universidad Nacional Agraria La Molina, Lima, Perú.

Oliva F. E. 1987. Factores de Corrección para edad en Vacas Lecheras Holstein de la cuenca lechera de Lima Tesis Ing. Zootecnista, Universidad Nacional Agraria La Molina, Lima, Perú.

Pallete P. A. Calderón V. J. y Arauco P. R. 1993. Características de Productividad de cuatro cuencas lecheras - Asociación Peruana de Producción Animal XVI Reunión Científica Anual, Piura, Perú.
Pallete, A.; Garcia, M. y Cespedes, P. 2005. Características de Productividad de Vacas en la cuenca lechera de Lima. Asociación Peruana de Producción Animal XXVII Reunión Científica Anual, Iquitos, Perú.

Pimentel F. E 1994. Caracterización de la Ganadería Lechera del Proyecto Majes. Tesis Ing. Zootecnista, Universidad Nacional Agraria La Molina, Lima, Peru.

Plan Nacional de Desarrollo Ganadero 2006-2015 Ministerio de Agricultura, Lima, Perú.

Rosales E. S. 2012. Evaluación de los Factores que afectan la Producción de leche en vacas Holstein en un establo de Puente Piedra, período 1995 - 2002 Trabajo Monográfico Ing. Zootecnista, Universidad Nacional Agraria La Molina, Lima, Perú.

Rosemberg B. M. 1976. Factores de Corrección por días vacíos en Lactaciones de Vacas Holstein Tesis Ing. Zootecnista, Universidad Nacional Agraria La Molina, Lima, Perú.

Ruiz, P. M. 2000. Productividad de las Hijas de Toros Nacionales e Importados en un Establo de la cuenca lechera de Lima. Tesis Ing. Zootecnista, Universidad Nacional Agraria La Molina, Lima, Perú.

Valera, M. L. 1996. Productividad de Vacas Holstein en la cuenca lechera de Lima y la magnitud de algunos Factores Ambientales que lo Afectan Tesis Ing. Zootecnista, Universidad Nacional Agraria La Molina, Lima, Perú.

Vassallo F. G. 1980. Índices Pecuarios y Caracterización de la Curva de Producción de Leche de Ganado Brown Swiss criado a 3500 metros de altura. Tesis Magister Scientiae, Escuela Postgrado, Especialidad de Producción Animal, Universidad Nacional Agraria La Molina, Lima, Perú. 